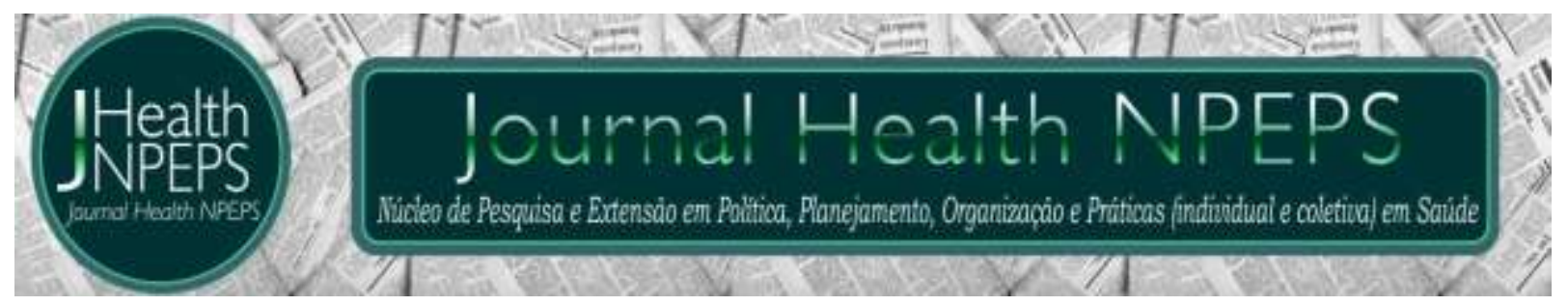

ARTIGO ORIGINAL

\title{
RISCOS OCUPACIONAIS E ADOECIMENTOS ENTRE PROFESSORES DA REDE MUNICIPAL DE ENSINO
}

\section{OCCUPATIONAL HAZARDS AND ILLNESS AMONG TEACHERS OF THE MUNICIPAL SCHOOL SYSTEM}

\section{RIESGOS LABORALES Y LA ADOECIMENTOS ENTRE LOS DOCENTES DE LA RED MUNICIPAL DE ENSEÑANZA}

\begin{abstract}
Luiz Almeida da Silva ${ }^{1}$, Jéssica Nayara Fritsch ${ }^{2}$, Rita de Cácia de Marchi Barcelos Dalri $^{3}$, Giulena Rosa Leite ${ }^{4}$ Ludmila Grego Maia $^{5}$, Sebastião Elias da Silveira ${ }^{6}$, Renata Alessandra Evangelista ${ }^{7}$, Bruno Bordin Pelazza ${ }^{8}$
\end{abstract}

\section{RESUMO}

Objetivo: o presente trabalho objetivou identificar o conhecimento dos professores da rede municipal de educação sobre os riscos ocupacionais do seu ambiente de trabalho e as causas dos seus adoecimentos. Método: estudo transversal, quantitativo, realizado com 33 professores da rede municipal de ensino que foram afastados por doença relacionada ao trabalho em 2013. O estudo seguiu os preceitos ético-legais e recebeu sua aprovação por meio do protocolo CAAE: 30585114.5.0000.5083. Resultados: entre os entrevistados $90,9 \%$ são do sexo feminino, com média de $17,13 \pm 4,99$ anos de profissão, média de idade de 45,79 $\pm 9,82$, média de afastamento de 28,45 $\pm 38,05$ dias/ano. A variável frequência do adoecimento mostrou significância quando comparada ao desenvolvimento de prevenção de doenças no trabalho $(p=0,016) ; 66,7 \%$ reconhecem os riscos ocupacionais no ambiente laboral, ocorrendo adoecimentos por riscos ergonômicos e psicossociais (33,3\%). Todas as categorias cruzadas entre atestados e relatos dos trabalhadores mostraram bom entendimento para as causas de afastamentos, sendo respiratório $(p=0,02)$, psicossocial $(p=0,001)$, osteomuscular $(p=0,001)$, ginecológico

\footnotetext{
1 Enfermeiro. Pós-Doutor em Ciências da Saúde. Professor do Curso de Enfermagem Regional Jataí e orientador do Programa de Pós Graduação em Ensino na Saúde - UFG. E-mail: enferluiz@yahoo.com.br Autor principal - Endereço para correspondência: Rod BR 364 KM 192 - Setor Parque Industrial $\mathrm{n}^{\circ} 3800 . \quad$ Jataí-GO. Caixa Postal 03 - CEP 75801-615.

2 Enfermeira. Residente multiprofissional no Hospital de Doenças Tropicais - HDT, Goiânia, Goiás. E-mail: jessicafritsch@hotmail.com

${ }^{3}$ Enfermeira. Pós-Doutora em Ciências pela Escola de Enfermagem de Ribeirão Preto da Universidade de São Paulo EERP-USP. E-mail: ritacmbdalri@uol.com.br

${ }^{4}$ Enfermeira. Doutoranda em Ciências da Saúde. Professora e Coordenadora do Curso de Enfermagem da Regional Jataí da Universidade Federal de Goiás. E-mail: giulenar@gmail.com

${ }^{5}$ Enfermeira. Professora Assistente do Curso de Enfermagem Regional Jataí. Doutoranda em Ciências da Saúde. Email: Igregomaia@yahoo.com.br

${ }^{6}$ Enfermeiro. Mestre em Geografia da Saúde. Enfermeiro Intensivista e Chefe de área no Hospital das Clínicas da Universidade Federal de Uberlândia. E-mail: tiao_elias@yahoo.com.br

7 Enfermeira. Professora Adjunto do Curso de Enfermagem Regional Catalão e Orientadora do Programa de PósGraduação em Gestão Organizacional da Universidade Federal de Goiás. E-mail: evangelrae@gmail.com

${ }^{8}$ Enfermeiro. Doutorando em Ciências da Saúde. Professor do Curso de Enfermagem Regional Jataí, Universidade Federal de Goiás. E-mail: bordizim@hotmail.com
} 
$(p=0,001)$. Conclusão: professores reconhecem a existência dos riscos ocupacionais no ambiente de trabalho com ênfase no risco ergonômico e psicossocial realizam medidas de prevenções e não desejam mudar de área de atuação.

Descritores: Riscos Ocupacionais; Doença; Docentes.

\section{ABSTRACT}

Objective: this study aimed to identify the knowledge of teachers of municipal education on occupational hazards of their work environment and the causes of their illnesses. Method: cross-sectional, quantitative study conducted with 33 teachers of public schools that have been removed by occupational disease in 2013. The study followed the ethical and legal precepts and received approval by the CAAE protocol: 30585114.5.0000.5083 Results: of respondents, $90.9 \%$ are female, with a mean of 17.13 \pm 4.99 years profession, a mean age of $45.79 \pm 9.82$, departure from average $28.45 \pm$ 38.05 days /year. The variable frequency of illness showed significance when compared to the development of disease prevention at work ( $p=0.016) ; 66.7 \%$ recognize the occupational hazards in the work environment, occurring illnesses for ergonomic and psychosocial risks (33.3\%). All categories cross between certificates and workers' reports showed good understanding of the causes of sick leave, and respiratory $(p=0.02)$, psychosocial $(p=0.001)$, musculoskeletal $(p=0.001)$, gynecological $(p=0.001)$. Conclusion: teachers recognize the existence of occupational hazards in the workplace with an emphasis on ergonomic and psychosocial risk conduct contingency measures and do not wish to change their area of operation.

Descriptors: Occupational Risks; Disease; Faculty.

\section{RESUMEN}

Objetivo: este estudio pretende identificar los conocimientos de los profesores de la educación municipal en la occupational hazards de su ambiente de trabajo y las causas de su adoecimentos. Método: estudio transversal, cuantitativo, realizado con 33 profesores de la enseñanza municipal que estaban destrozadas por enfermedades relacionadas con el trabajo en 2013. El estudio siguió los preceptos ético-legal y recibió la aprobación a través del Protocolo de CAAE: 30585114.5.0000.5083. Resultados: de los encuestados, $90.9 \%$ son mujeres, con promedio de $17.13 \pm 4,99$ años de profesión, edad media de $45.79 \pm 9.82$, eliminación de 28.45 promedio $\pm 38,05$ días al año. La variable de la frecuencia de la enfermedad mostró significación en comparación con el desarrollo de la prevención de enfermedades en el trabajo ( $p=0,016) ; 66.7 \%$ reconoce los peligros ocupacionales en el ambiente de trabajo, que se producen adoecimentos los riesgos ergonómicos y psicosociales (33.3\%). Todas cruzadas de categorías entre certificados y cuentas de los trabajadores demostraron la comprensión de las causas de las salidas y vías respiratorias $(p=0,02)$, psicosocial $(p=0,001)$, musculoesqueléticos $(p$ $=0,001)$, ginecológicas $(p=0,001)$. Conclusión: profesores reconocen la existencia de los riesgos profesionales en el ambiente de trabajo con énfasis en lo psicosocial y ergonómico riesgo medidas de prevención y no desea cambiar su área de especialización.

Descriptores: Riesgos Laborales; Enfermedad; Docentes.

\section{INTRODUÇÃO}


A educação é entendida como uma das formas de contribuição para o convívio social, pois é por meio desta, que é possível a comunicação e convivência com outras pessoas. 0 ambiente responsável pelos ensinamentos de educação é denominado Escola. As criações das escolas ocorreram pela necessidade do meio social dos indivíduos, sendo imprescindível o surgimento de locais para o aprendizado da escrita e leitura, todavia, estas instituições eram privadas, não permitindo o ingresso de grande parte da população ${ }^{1}$.

As mudanças no sistema de ensino ocorridas na década de sessenta quando novas pedagogias foram implantadas junto com a criação do Ministério da Educação, buscavam ampliar o atendimento à educação para as pessoas que anteriormente não tinham acesso a este serviço. Estas mudanças desencadearam transformações nos aspectos físicos e organizacional do sistema educativo como o aumento no número de matrículas, turmas e alunos por sala modificando a qualidade da atividade prestada pelo professor e acabando por aumentar a quantidade de trabalho deste profissional passando a responsabilidade de ensinar e educar o aluno a ele ${ }^{1,2}$.

Desta forma, as mudanças acima citadas passaram a aumentar ainda mais a sobrecarga de trabalho para os docentes expondo-os a riscos ocupacionais por provocarem um esforço físico e cognitivo, além das suas possibilidades com um quadro favorável ao surgimento de ansiedade, depressão, estresse e outras doenças desencadeadas pelo ambiente de trabalho ${ }^{1}$.

As causas que afetam a saúde do trabalhador estão determinadas pelos fatores de riscos ocupacionais que podem ser: físicos, químicos, biológicos, mecânicos e aqueles decorrentes da organização laboral presentes do processo de trabalho e os condicionantes sociais, econômicos, tecnológicos e organizacionais responsáveis pela condição de vida e saúde do trabalhador ${ }^{3}$.

Para melhor classificação dos agravos à saúde do trabalhador, estes foram classificados em dois grupos: no primeiro incluem-se aqueles que traduzem ruptura abrupta do equilíbrio entre as condições e o ambiente de trabalho e a saúde do trabalhador como os acidentes de trabalho e as intoxicações agudas de origem profissional. O segundo grupo inclui agravos de caráter crônico: a doença profissional típica, definida como aquela inerente ou peculiar a determinado ramo de atividade 4 .

Ainda outro grupo que podemos citar são as doenças relacionadas ao trabalho, definidas como agravos que adicionadas às doenças profissionais, legalmente 
desconhecidas e ocorridas com trabalhadores nos ambientes e ou condições insalubres contribuem significativamente para a ocorrência de doenças entre os profissionais expostos a estes fatores, porém a graus variados de magnitude ${ }^{5}$.

O professor na sociedade, por seu papel relevante sendo responsável pelo preparo do aluno como cidadão necessita que suas condições de trabalho sejam adequadas para atenuar os riscos ocupacionais. 0 educador que possui um desgaste no trabalho devido a fatores não compensatórios como um salário não apropriado, descaso e insatisfação, combinados com o não acesso adequado a bens e serviços e uma desvalorização profissional e social encontra-se em vulnerabilidade ocupacional6.

Estudos na área de Saúde Ocupacional evidenciam que os processos de desgaste do corpo são determinados em boa parte pelo tipo de trabalho e pela forma como esse é desempenhado. Uma das maneiras de reconhecer as doenças relacionadas ao trabalho é analisar os motivos que levam os trabalhadores a se incapacitarem para o trabalho ${ }^{7}$.

Por meio do atendimento de uma equipe especializada em Saúde do Trabalhador é possível obter-se garantia de bem estar dos educadores. Acredita-se na necessidade de ações envolvendo programas de promoção de saúde, prevenção de doenças, proteção, manutenção e recuperação da saúde desta categoria profissional, desta forma contribuindo para a construção de uma sociedade saudável ${ }^{6}$.

A luta pela saúde dos trabalhadores está presente em todos os setores, mas entendemos que as ações de saúde relacionadas aos professores se fazem emergentes.

Diante dos fatos presenciados cotidianamente referentes aos agravos à saúde destes trabalhadores surgiu-nos o seguinte questionamento que servirá como questão norteadora do presente estudo: Qual o conhecimento sobre os riscos ocupacionais e as causas dos adoecimentos dos professores da rede municipal de educação de um município do Sudoeste Goiano?

Estudar a forma de adoecimento dos professores por meio de suas práticas trabalhistas pode contribuir para a criação de medidas preventivas, ações corretas de prevenção de doenças, promovendo entre os profissionais de enfermagem do trabalho o conhecimento dos assuntos referentes à problemática e assim despertando para estudos e pesquisas que possam ajudar a mudar o atual cenário de saúde desses trabalhadores no Brasil. Assim, o presente estudo objetivou identificar o conhecimento dos professores da rede municipal de educação sobre os riscos ocupacionais do seu ambiente de trabalho e as causas dos seus adoecimentos. 


\section{MÉTODO}

O presente estudo possui caráter quantitativo de natureza transversal. A escolha por este método de pesquisa decorreu pela necessidade das coletas dos dados serem realizadas em um único momento por meio da utilização de questionários e após realizar-se a mensuração das opiniões e atitudes do público alvo do estudo ${ }^{8}$.

Para a seleção dos participantes no estudo foram pré estabelecidos os critérios: ser docente do quadro da Secretaria Municipal de Educação do município em estudo; estar ativo em instituições de ensino na zona urbana, tendo em vista a dificuldade encontrada na logística de acesso às unidades rurais; ter apresentado atestado médico no ano de 2013 com período de afastamento das atividades superior a três dias-sendo o motivo de adoecimento decorrente do exercício da profissão, conforme constar no Código Internacional de Doenças presente no atestado.

Os dados foram coletados no período de agosto a outubro de 2014. Para tal coleta fez- se necessário organizá-la em etapas.

A primeira ocorreu entre os meses de agosto e setembro de 2014 no Departamento de Divisão Administrativa da Secretaria Municipal de Educação de um município do Sudoeste Goiano. Nesta etapa foram acessados 629 atestados disponibilizados pela Instituição no período de janeiro a dezembro de 2013. Mediante a posse dos atestados foi realizada uma avaliação documental pelos pesquisadores permitindo a identificação das causas de afastamento e do período de ausência dos profissionais na atividade de docência. Após esta fase de avaliação documental foram excluídos 468 atestados conforme critério de seleção do estudo, permanecendo para a segunda avaliação documental 161(43\%) atestados pertencentes a professores com período de ausência de suas funções superior a três dias.

$\mathrm{Na}$ terceira avaliação documental foram selecionados para o estudo os docentes que, além dos três dias ou mais de afastamento apresentaram o CID relacionado a doença ocupacional, sendo que nesta etapa foram excluídos 69 atestados restando para o estudo uma amostragem de $92(57 \%)$ atestados correspondentes a 55 professores.

Ressalta-se que o cálculo amostral não foi realizado por ter sido trabalhado com toda a população que apresentou os critérios de seleção na pesquisa. 
Na segunda etapa desenvolveu-se a pesquisa de campo no mês de outubro de 2014 nos locais de trabalho dos docentes, sendo a entrevista previamente agendada por meio de contato telefônico conforme disponibilidade dos profissionais pertencentes à amostra selecionada. A aplicação do questionário semi-estruturado, elaborado e aplicado pelos autores, contendo 14 questões foi realizada de forma direta com os participantes da pesquisa, a fim de possibilitar a explicação e responder dúvidas existentes referente ao estudo.

Aos professores que concordaram em participar da pesquisa, após exposição sobre as informações, os riscos, os benefícios e os objetivos da pesquisa foi disponibilizado o Termo de Consentimento Livre Esclarecido (TCLE), o qual foi devidamente assinado em duas vias, ficando uma em poder do pesquisador e outra com o participante da pesquisa.

No decorrer das entrevistas, 22 professores foram excluídos do estudo devido as seguintes justificativas: nove professores por seu adoecimento não se tratar da origem do ambiente de trabalho ou da atividade exercida, segundo relato dos mesmos, seis por terem seus contratos de serviço exonerados, dois por aposentadoria no ano de 2014, quatro por estarem de licença médica e um por desistir após a seleção. Sendo assim a amostra total dos participantes do estudo foram de 33 profissionais da área da educação.

A terceira e última etapa constituiu-se na análise dos dados, os quais foram inseridos em um banco de dados por meio de dupla digitação em planilha Excel e posteriormente realizada a análise por meio da utilização do software Statistical Package for Social Science (SPSS) versão 16.0.

O programa Microsoft $®$ Excel 2007 foi usado para tabulação dos dados e a análise estatística foi realizada pelo programa SPSS $₫$ for Windows ${ }^{\circledR}$, versão 16.0.

Para avaliar a influência das variáveis frequência de adoecimento, estratégias de prevenção, percepção do trabalho, mudar de trabalho em relação às variáveis sexo, idade, tempo de serviço, percepção do trabalho, atendimento fornecido pela secretaria, influência do apoio fornecido pela secretaria, utilização de prevenção, vontade de mudar de trabalho, foi utilizado o teste Qui- Quadrado e Exato de Fisher.

Para comparar as variáveis Causas de Adoecimento Relatados (CID) em relação às variáveis Causas de Adoecimento Classificados nos Atestados (CID) foi utilizado o teste Exato de Fisher. Foi utilizado como nível de significância o valor $5 \%(p<0,05)$. 
Destacamos que foi respeitada a resolução de $n^{\circ} 466$ de 12 de dezembro de 2012, o projeto foi submetido à Comitê de Ética em Pesquisa por meio da Plataforma Brasil e obteve sua aprovação sob o n CAAE: 30585114.5.0000.5083, parecer 636.340.

\section{RESULTADOS}

Conforme apresentado na Tabela 1, 90,9\% dos participantes eram do sexo feminino e 9,1\% do masculino. A média de idade dos entrevistados foi de 45,79 anos com tempo médio de serviço na profissão de 17,13 anos. Os períodos de dias afastados das funções laborais obtiveram a média 28,45 dias.

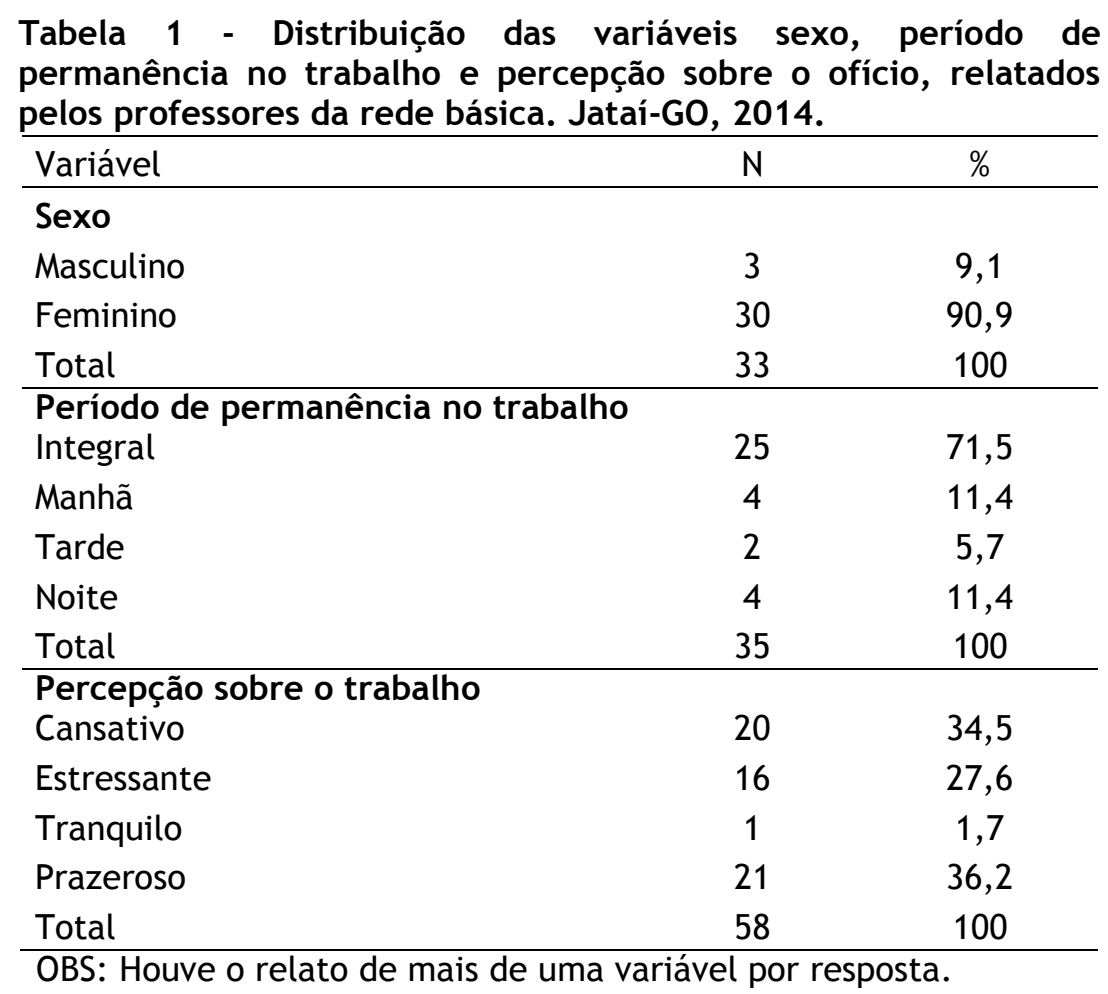

Os dados referentes à idade, tempo e dias de afastamento obtiveram as seguintes médias: Idade $(45,79 \pm 9,82)$ anos, tempo de serviço $(17,13 \pm 4,99)$ anos, dias de afastamento $(28,45 \pm 38,05)$ dias.

Com relação ao período de permanência no trabalho, 71,5\% dos professores responderam ser o seu expediente de serviço em período integral. Ao serem questionados a respeito da percepção sobre o seu ofício $36,2 \%$ relataram como prazeroso e $34,5 \%$ como cansativo (Tabela 1 ). 
Tendo em consideração os riscos ocupacionais estes foram apontados como existentes no ambiente de trabalho por $66,7 \%$ dos trabalhadores em contrapartida a $33,3 \%$ que referiram sua não existência. A possibilidade do adoecimento decorrente aos riscos ergonômicos e psicossociais foram citadas por 33,3\% dos entrevistados (Tabela 2).

\begin{tabular}{lcc}
$\begin{array}{l}\text { Tabela } 2 \text { - Distribuição das situações que afetam a saúde no } \\
\text { ambiente de trabalho segundo a percepção dos entrevistados, } \\
\text { Jataí - GO, 2014. }\end{array}$ & \multicolumn{1}{l}{} \\
\hline Variável & & \\
\hline Está exposto a riscos ocupacionais & 22 & 66,7 \\
Sim & 11 & 33,3 \\
Não & 33 & 100 \\
Total & & \\
\hline Risco ocupacional exposto & 4 & 10,3 \\
Físico & 13 & 33,3 \\
Ergonômico & 3 & 7,7 \\
Químico & 6 & 15,4 \\
Biológico & 13 & 33,3 \\
Psicossocial & 39 & 100 \\
Total & & \\
\hline Afeta a sua saúde no trabalho & 5 & 13,6 \\
Postura ereta prolongada & 9 & 24,3 \\
Sobrecarga de trabalho & 3 & 8,1 \\
Cansaço & 3 & 8,1 \\
Contato com pó de giz & 11 & 29,7 \\
Alterações psíquicas & 4 & 10,8 \\
Desgaste vocal & 2 & 5,4 \\
Não informado & 37 & 100 \\
Total &
\end{tabular}

As situações que afetam mais a saúde do professor no ambiente de trabalho (Tabela 3) foram citadas como sendo as alterações psíquicas $(29,7 \%)$, sobrecarga de trabalho $(24,3 \%)$ e a postura ereta prolongada $(13,6 \%)$.

Ao analisarmos a frequência do adoecimento pelo motivo que decorreu o afastamento das atividades profissionais no ano de 2013, 39,4\% dos entrevistados relataram ser de uma a duas vezes no ano, $27,3 \%$ a primeira vez que adoeceu e $21,2 \%$ afirmaram estarem sempre doentes (Tabela 3).

As causas do adoecimento e afastamento relatados pelos professores (Tabela 4) foram: osteomusculares $(31,8 \%)$, psicossociais $(18,2 \%)$, seguidas das doenças do sistema respiratório e cardiovascular ambas com $(11,4 \%)$.

As causas dos adoecimentos e afastamentos de acordo com os atestados 
encontrados na Secretaria de Educação foram: osteomusculares (30,5\%), psicossociais $(19,5 \%)$ e doenças do sistema respiratório e cardiovascular (16,7\%), conforme apresentados na Tabela 3.

Tabela 3 - Distribuição das variáveis frequência de adoecimento, causas do adoecimento segundo relato dos trabalhadores e causas do adoecimento segundo os atestados médicos apresentados à Secretaria de Educação, Jataí - GO, 2014.

\begin{tabular}{|c|c|c|c|}
\hline Variável & CID & $\mathbf{n}$ & $\%$ \\
\hline \multicolumn{4}{|c|}{ Frequência do adoecimento em 2013} \\
\hline Uma vez & & 9 & 27,3 \\
\hline 1 a 2 vezes & & 13 & 39,4 \\
\hline 3 a 4 vezes & & 4 & 12,1 \\
\hline$>4$ vezes & & 7 & 21,2 \\
\hline Total & & 33 & 100,0 \\
\hline \multicolumn{4}{|c|}{ Causas dos adoecimentos segundo os profissionais } \\
\hline Doenças infecciosas e parasitárias & (A00-B99) & 2 & 4,5 \\
\hline Distúrbios do sistema respiratório & $(\mathrm{J} 00-\mathrm{J} 99)$ & 5 & 11,4 \\
\hline Distúrbios psicossociais & (F00-F99) & 8 & 18,2 \\
\hline Distúrbios osteomusculares & (M00-M99) & 14 & 31,8 \\
\hline Distúrbios cardiovasculares & $(100-199)$ & 5 & 11,4 \\
\hline Distúrbios ginecológicos & $(000-099)$ & 3 & 6,8 \\
\hline Não informadas & & 2 & 4,6 \\
\hline Total & & 44 & 100,0 \\
\hline \multicolumn{4}{|c|}{ Causas dos adoecimentos segundo os atestados apresentados } \\
\hline Doenças infecciosas e parasitárias & (A00-B99) & 3 & 8,3 \\
\hline Distúrbios do sistema respiratório & $(\mathrm{J} 00-\mathrm{J99})$ & 6 & 16,7 \\
\hline Distúrbios psicossociais & (F00-F99) & 7 & 19,5 \\
\hline Distúrbios osteomusculares & (M00-M99) & 11 & 30,5 \\
\hline Distúrbios cardiovasculares & $(100-199)$ & 6 & 16,7 \\
\hline Distúrbios ginecológicos & $(000-099)$ & 3 & 8,3 \\
\hline Total & & 36 & 100,0 \\
\hline
\end{tabular}

OBS: Houve o relato de mais de uma variável por resposta.

Quando questionados sobre a assistência fornecida pela Secretaria de Educação ou da Instituição de ensino que trabalham ou trabalhavam e como esta poderia ter ajudado na sua recuperação, 90,9\% dos entrevistados relataram não ter tido amparo por nenhuma das unidades, $38,9 \%$ dos professores não souberam responder como poderia ser esse auxilio, 27,8\% acreditavam que a assistência poderia ter servido como meio para a agilidade do tratamento e $19,4 \%$ dos profissionais acreditavam que serviria como valorização profissional elevando sua autoestima.

Devido ao risco de novas alterações no estado de saúde e agravamentos das já existentes preocupamos-nos em verificar se está sendo realizada pelos professores 
selecionados para o estudo medidas de prevenções de adoecimentos. Percebemos que $57,6 \%$ dos professores realizam esta prática sendo o acompanhamento médico e redução da carga de trabalho citadas por 30\% deles.

Quando indagados sobre o desejo de mudar de trabalho ou área de atuação, $12,1 \%$ responderam sim e $87,9 \%$ responderam não para a pergunta. Observamos que entre os entrevistados que apresentaram resposta afirmativa, 100,0\% acreditavam ser o ambiente de trabalho propício para um novo adoecimento.

Com relação aos professores que responderam não ao questionamento, 40,0\% relataram sentir prazer na profissão escolhida, 31,4 não informaram a causa e 17,2\% responderam que não desejavam a mudança por estarem próximos de serem aposentados.

Tabela 4 - Análise dos fatores associados entre frequência do adoecimento em relação às variáveis sexo, atendimento fornecido pela Secretaria de Educação, desenvolvimento de prevenção e mudança de profissão. Jataí - GO, 2014.

\begin{tabular}{|c|c|c|c|c|c|c|c|c|c|}
\hline \multirow{3}{*}{ Variável } & \multicolumn{8}{|c|}{ Frequência do adoecimento } & \multirow{3}{*}{$P$} \\
\hline & \multicolumn{2}{|c|}{$1 \mathrm{vez}$} & \multicolumn{2}{|c|}{1 a 2 vezes } & \multicolumn{2}{|c|}{3 a 4 vezes } & \multicolumn{2}{|c|}{$>4$ vezes } & \\
\hline & $\mathrm{n}$ & $\%$ & $\mathrm{n}$ & $\%$ & $\mathrm{n}$ & $\%$ & $\mathrm{n}$ & $\%$ & \\
\hline \multicolumn{10}{|l|}{ Sexo } \\
\hline Masculino & 2 & 22,2 & 1 & 7,7 & 0 & 0,0 & 0 & 0,0 & \\
\hline Feminino & 7 & 77,8 & 12 & 92,3 & 4 & 100 & 7 & 100 & \\
\hline Total & 9 & 100 & 13 & 100 & 4 & 100 & 7 & 100 & 0,390 \\
\hline \multicolumn{10}{|c|}{ Atendimento fornecido pela SE* } \\
\hline Sim & 0 & 0,0 & 1 & 7,7 & 0 & 0,0 & 2 & 28,6 & \\
\hline Não & 9 & 100 & 12 & 92,3 & 4 & 100 & 5 & 71,4 & \\
\hline Total & 9 & 100 & 13 & 100 & 4 & 100 & 7 & 100 & 0,208 \\
\hline \multicolumn{10}{|c|}{ Desenvolvem prevenção } \\
\hline Sim & 2 & 22,2 & 7 & 53,8 & 3 & 75 & 7 & 100 & \\
\hline Não & 7 & 77,8 & 6 & 46,2 & 1 & 25 & 0 & 0,0 & \\
\hline Total & 9 & 100 & 13 & 100 & 4 & 100 & 7 & 100 & 0,016 \\
\hline \multicolumn{10}{|l|}{ Mudaria de profissão } \\
\hline Sim & 1 & 11,1 & 1 & 7,70 & 1 & 25 & 1 & 14,3 & \\
\hline Não & 8 & 88,9 & 12 & 92,3 & 3 & 75 & 6 & 85,7 & \\
\hline Total & 9 & 100 & 13 & 100 & 4 & 100 & 7 & 100 & 0,825 \\
\hline
\end{tabular}

Nas associações entre a frequência do adoecimento com as variáveis sexo, atendimento fornecido pela Secretária Municipal de Educação ou Instituição de Trabalho, mudaria de profissão não apresentaram significância estatística $(p>0,05) ; 0$ cruzamento com a variável desenvolve prevenção obteve significância $(p=0,016)$. 
$\mathrm{Na}$ análise descritiva entre frequência do adoecimento comparada a tempo de serviço não se observou significância entre as médias.

Tabela 5 - Análise dos fatores associados entre desejo de mudança de profissão com as variáveis, como esse apoio poderia influenciar. Jataí-GO, 2014.

\begin{tabular}{|c|c|c|c|c|c|}
\hline \multirow{3}{*}{ Variável } & \multicolumn{4}{|c|}{ Mudaria de profissão } & \multirow{3}{*}{$\mathbf{P}$} \\
\hline & \multicolumn{2}{|c|}{ Sim } & \multicolumn{2}{|c|}{ Não } & \\
\hline & $\mathbf{N}$ & $\%$ & $\mathrm{n}$ & $\%$ & \\
\hline \multicolumn{6}{|c|}{ Como esse apoio poderia ter influenciado } \\
\hline \multicolumn{6}{|c|}{ Agilidade no tratamento } \\
\hline Sim & 1 & 25,0 & 9 & 31,0 & \\
\hline Não & 3 & 75,0 & 20 & 69,0 & \\
\hline Total & 4 & 100 & 29 & 100 & 0,806 \\
\hline \multicolumn{6}{|l|}{ Valorização profissional } \\
\hline Sim & 3 & 75,0 & 4 & 13,8 & \\
\hline Não & 1 & 25,0 & 25 & 86,2 & \\
\hline Total & 4 & 100 & 29 & 100 & 0,005 \\
\hline \multicolumn{6}{|c|}{ Prevenção do adoecimento } \\
\hline Sim & 0 & 0,0 & 5 & 17,2 & \\
\hline Não & 4 & 100 & 24 & 82,8 & \\
\hline Total & 4 & 100 & 29 & 100 & 0,367 \\
\hline \multicolumn{6}{|l|}{ Não souberam informar } \\
\hline Sim & 1 & 25,0 & 13 & 44,8 & \\
\hline Não & 3 & 75,0 & 16 & 55,2 & \\
\hline Total & 4 & 100 & 29 & 100 & 0,452 \\
\hline
\end{tabular}

Nas associações entre mudaria de profissão com as variáveis agilidade no tratamento, prevenção do adoecimento e não souberam informar, não apresentaram significância estatística $(p>0,05)$; já o cruzamento com a variável valorização profissional obteve significância $(p=0,05)$.

Com relação a associações entre as variáveis causa do adoecimento segundo relato dos profissionais e causa do adoecimento segundo os atestados apresentados à Secretária Municipal de Educação observamos que houve algumas divergências entre o entendimento do professor sobre a causa de seu adoecimento, contudo, não houve significância nestas diferenças $(p>0,05)$. Quando a variável foi cruzada com a mesma causa observou-se as seguintes significâncias: variáveis sistema respiratório e sistema respiratório $(p=0,02)$; variáveis psicossocial e psicossocial $(p=0,001)$; variáveis osteomuscular e osteomuscular $(\mathrm{p}=0,001)$; variáveis cardiovascular e cardiovascular $(p=0,001)$; variáveis ginecológico e ginecológico $(p=0,001)$, mostrando haver concordância entre o que está descrito no atestado e a que o trabalhador atribuiu a seu adoecimento. 


\section{DISCUSSÃO}

Os profissionais da educação participantes deste estudo foram na maioria do sexo feminino, representando um total de $90,9 \%$ da amostra. A média de idade de todos os entrevistados foi de 45,79 anos sendo que $71,5 \%$ dos professores trabalham em período integral com tempo médio de serviço na profissão de 17,13 anos. Estes achados assemelham-se ao estudo cuja população estudada foi constituída por professores em sua maioria mulheres $(82,8 \%)$ com idade média de 40,7 anos, carga horária média semanal de trabalho de 38,23 horas e tempo de atuação como professor em média de 11,5 anos$^{9}$.

A grande concentração de mulheres atuando na área educacional se deve ao processo histórico da entrada da mulher no mercado de trabalho. Estas assumiram o processo de ensino como continuidade do cuidado exercido em suas práticas domésticas e assim assumindo um papel de mãe educadora. Ainda nos dias atuais observamos a profissão de docência ser vinculada a tarefa feminina ${ }^{10}$.

Quando questionamos os docentes a respeito da percepção sobre o seu ofício, $36,2 \%$ deles relataram ter prazer em exercer sua profissão e 34,5\% descreveram-na como cansativa. Estudo mostrou que quanto maior a demanda que a escola deve responder, mais complexas e cansativas se tornam as atividades dos docentes. Vale ressaltar que 0 ambiente escolar espera do professor preparo, formação e estímulo para exercer o domínio em sala de aula e estes, muitas vezes se deparam com situações a qual não estão preparados. Sugiro padronizar no texto professor ou docente 2 .

Quando analisados os riscos ocupacionais foi detectado que $66,7 \%$ dos profissionais afirmaram a existência deles. Os riscos ergonômicos e psicossociais foram os mais citados como possíveis causadores dos adoecimentos com 33,3\%. Referente às situações que afetam a saúde do docente no ambiente de trabalho as alterações psíquicas representaram $29,7 \%$ de sua totalidade; a sobrecarga de trabalho $(24,3 \%)$ e a postura ereta prolongada $(13,6 \%)$, estas foram as que receberam maior destaque. Vale esclarecer que as alterações psíquicas estão relacionadas ao risco psicossocial, assim como a sobrecarga de trabalho e a postura ereta prolongada ao risco ergonômico.

Um estudo realizado em um município situado na região noroeste do Rio Grande do Sul com uma amostra de 34 professores universitários evidenciou que em relação aos riscos ocupacionais, $73,5 \%$ dos docentes pesquisados os identificaram como presente no 
seu cotidiano e no ambiente laboral. Os riscos psicossociais foram descritos por $11 \%$ dos entrevistados e os riscos ergonômicos corresponderam a $13 \%$ das respostas obtidas ${ }^{11}$.

Observou-se também, na pesquisa supracitada que nas declarações dos professores entrevistados prevaleceu o relato de ansiedade $(63,6 \%)$ e a depressão $(18,1 \%)$, atribuídas à sobrecarga de trabalho e o estresse como principais causadores desta sobrecarga. Com relação aos docentes que apresentaram queixas osteomusculares decorrentes da ocupação profissional, as dores referidas por eles estão associadas aos longos períodos em pé e às tensões no ambiente de trabalho ${ }^{11}$.

A sobrecarga de trabalho não desencadeia diretamente as alterações psíquicas. O problema surge quando essa sobrecarga está relacionada com a falta de autonomia e em consequência, as alternativas para se lidar com está situação ficam muito restritas ${ }^{12}$.

Com relação às associações entre as variáveis causas dos adoecimentos segundo os relatos dos profissionais entrevistados e causas dos adoecimentos em concordância com os atestados apresentados à Secretaria Municipal de Educação observamos as seguintes significâncias: variáveis sistema respiratório e sistema respiratório $(p=0,02)$ observamos que $20 \%$ dos docentes que apresentaram atestados não identificaram seu adoecimento por esta causa; variáveis psicossocial e psicossocial $(p=0,001), 25 \%$ dos professores que apresentaram atestados devido essa causa negaram o seu adoecimento por este motivo; variáveis osteomuscular e osteomuscular $(p=0,001), 21,4 \%$ dos professores que apresentaram atestados devido esta causa negaram que seu adoecimento seja recorrente a esta origem; variáveis cardiovascular e cardiovascular $(p=0,001)$, todos os entrevistados que apresentaram atestados confirmaram ser esta a origem do seu adoecimento; variáveis ginecológicas e ginecológicas $(p=0,001)$, todos os entrevistados que apresentaram atestados confirmaram ser esta a origem do seu adoecimento.

Estudo realizado com professores em uma instituição de ensino privada no município de Niterói/RJ no qual observou que as principais causas de adoecimento destes profissionais foram as doenças osteomusculares $(18,75 \%)$, respiratórias $(14,58 \%)$, seguidas de cardiovasculares e vocais, ambas com (10,42\%). Dentre as doenças citadas acima as que mais propiciaram os afastamentos laborais, foram as osteomusculares (25\%), geniturinárias $(15,63 \%)$ e respiratórias $(12,05 \%)$. Observamos a semelhança com o estudo aqui realizado no que se refere as doenças osteomusculares. Entretanto no que 
diz respeito às doenças respiratórias e cardiovasculares essas sobrepõem as doenças psicossociais divergindo da pesquisa aqui realizada ${ }^{13}$.

Um outro estudo realizado com professores universitários de Campinas/SP, evidenciou que a maior queixa apresentada pelos profissionais, ou seja $85,71 \%$, foram os problemas de saúde relacionados à esfera emocional e que estes estavam associados ao estresse no trabalho e indisciplina na sala de aula. Os autores acreditam ser notório que a indisciplina em sala de aula resulta em desgaste emocional do professor que se encontra em contato direto com os alunos. Além do estado de tensão emocional, os docentes mantêm-se em pé para melhor controle dos alunos. Dessa forma, as tensões tanto emocionais quanto corporais podem desencadear queixas osteoarticulares ${ }^{14}$.

Os geradores de estresse no ambiente de trabalho podem ser os fatores ambientais tanto quanto as exigências físicas e mentais. As condições ambientais como ruído, temperatura, vibração, iluminação e poluição tem sido apontadas como estressores produzidos no ambiente de trabalho. No que se referem à organização do trabalho, atividades monótonas, repetitivas e fragmentadas, sobrecarga, conflito e ambiguidade de papel, também são ressaltados como possíveis estressores ${ }^{15}$.

As condições de trabalho e saúde do professor universitário perceberam que as queixas osteomusculares estavam relacionadas às atividades do profissional como os longos tempos de permanência em pé, carregar material didático para salas de aulas, responsabilidade pela instalação de recursos audiovisuais, entre outros ${ }^{15}$.

Estudos realizados verificaram que as formas encontradas pelos professores para lidar com os problemas de saúde existentes neles, problemas no ambiente escolar como infraestrutura precária, recursos materiais limitados, baixos salários e pouca valorização profissional ocorre por meio do absenteísmo e possivelmente o abandono da profissão ${ }^{16,17}$.

0 professor que sente prazer em exercer a sua profissão mostra-se convicto e consciente da sua importância para a sociedade. Para ele ensinar é visto como uma vocação. O amor à profissão e o reconhecimento da sua importância social se mostram, mais uma vez, como valores incontestável ${ }^{18}$.

Os resultados apresentados nos levam a perceber que os professores entrevistados gostam de sua profissão e tem a intenção de nela continuar, o que nos remete a ideia de bem-estar e satisfação profissional.

Ao analisarmos a frequência do adoecimento pelo motivo que decorreu o afastamento das atividades profissionais no ano de 2013, 39,4\% dos professores relataram ser de uma a duas vezes no ano, $27,3 \%$ a primeira vez que adoeceu e $21,2 \%$ 
afirmaram estar sempre doentes. Quando tal fator foi cruzado com a capacidade de desenvolvimento de prevenção, os valores mostraram significância $(p=0,016)$, evidenciando que os profissionais ainda tendem a buscar estratégias de prevenção apenas quando os afastamentos são recorrentes.

Ao ser analisada a frequência do adoecimento com idade e tempo de serviço não houve significância $(p>0,05)$.

Quando o professor apresenta sintomas de esgotamento físico e mental passa a utilizar o absenteísmo, solicitação de atestados e/ou licenças médicas e licenças sem vencimento como mecanismo de defesa para lidar com a realidade advinda da sua prática $^{19}$.

O período de dias afastados das funções laborais foi em média 28,45 dias. Nesse contexto apresentado podemos inferir que a prática da docência a longo prazo pode originar diversas doenças podendo acarretar o absenteísmo no ambiente de trabalho.

Um estudo com professores da rede municipal de ensino de Natal/RN para avaliar o impacto da sintomatologia osteomuscular na qualidade de vida de professores. Destes, 51,5\% relataram ter realizado alguma consulta a profissional da saúde decorrente ao referido problema ${ }^{20}$.

Um estudo realizado em Vitória/ES objetivando discutir a intensificação do trabalho e suas implicações no modo de vida e na saúde de docentes do ensino público constatou que dentre os participantes um total de 78 professores $(81,3 \%)$ relataram ter procurado atendimento médico e/ou psicológico nos últimos dois anos. Dentre eles, $46,2 \%$ procurou esse atendimento entre uma e duas vezes por ano ${ }^{21}$.

Os professores participantes do estudo aqui realizado relataram em sua maioria (90,9\%), que não receberam nenhuma assistência da Secretaria Municipal de Educação ou da instituição de ensino que trabalham ou trabalhavam. Quando questionados sobre a forma que esse apoio poderia ter sido realizado, 38,9\% dos professores não souberam informar, 27,8\% acreditavam que a assistência por parte da Secretaria Municipal da Educação ou da Instituição de ensino que trabalham ou trabalhavam poderia ter servido como meio para a agilidade do tratamento e $19,4 \%$ dos profissionais acreditavam que a assistência serviria como valorização profissional elevando sua autoestima.

Por se tratar de instituições públicas, o atendimento ao trabalhador deveria ser fornecido através da Rede Nacional de Atenção Integral à Saúde do Trabalhador (RENAST) e sua rede de Centros de Referência em Saúde do Trabalhador (CEREST), 
contudo a estruturação desta rede enfrenta enormes obstáculos devido à limitada importância desta área na estrutura ministerial aliada a interesses políticos dificultando a implantação dos CERESTS e na sua constituição, atribuições e autonomias ${ }^{22}$. Desta forma reconhecemos as dificuldades das instituições em atender as principais queixas dos educadores.

Percebemos que 57,6\% dos professores realizam medidas de prevenções do adoecimento. Entre as principais práticas está o acompanhamento médico e a redução da carga de trabalho citadas por 30\% dos entrevistados.

Evidenciou-se que as doenças que mais afetaram a saúde dos professores foram as osteomusculares e as psicossociais, o que demonstra a necessidade dos profissionais de se prevenirem contra essas enfermidades. A redução de horas diárias de trabalho, assim como fazer pequenas pausas durante o período de serviço, ajuda a reduzir os sintomas do adoecimento musculoesquelético ${ }^{3}$.

A prática de atividade física além de prevenir as dores musculoesqueléticas promove o bem estar psicológico, reduz também o estresse, a ansiedade e a depressão.

Quando indagados sobre o desejo de mudar de trabalho ou área de atuação, $12,1 \%$ responderam sim e $87,9 \%$ responderam não para a pergunta. Observamos que entre os entrevistados que apresentaram respostas afirmativas, 100,0\% acreditam ser o ambiente de trabalho propício para um novo adoecimento.

Com relação aos professores que responderam não ao questionamento, 40,0\% relataram gostar da profissão escolhida, 31,4\% não informaram a causa e 17,2\% afirmaram que não desejam a mudança por estarem próximos de serem aposentados.

Quando analisado as variáveis desejo de mudar de profissão com a variável como o apoio recebido da Secretaria de Educação ou Instituição de trabalho poderia ter influenciado, observou-se significância estatística $(p=0,005)$, o qual mostra que mesmo os trabalhadores tendo a percepção da valorização profissional não querem mudar de emprego, expondo-se cada vez mais ao ambiente de trabalho.

O abandono da profissão demonstra ser um mecanismo de defesa encontrado pelo professor para fugir da realidade vivenciada do ambiente escolar.

\section{CONCLUSÃO}

O presente estudo apresentou a prevalência de mulheres no ambiente escolar e 
o sentimento de prazer e cansaço relacionado ao exercício da profissão. Os riscos ocupacionais foram percebidos como existentes entre os professores com prevalência do risco ergonômico e psicossocial.

Dentre as causas de afastamento das atividades de trabalho ressaltou-se as causas osteomusculares e psicossociais. Observamos por meio da divergência entre alguns atestados apresentados pela Secretaria Municipal de Educação e as causas do adoecimento relatadas pelos professores que ainda há uma falta de esclarecimento para alguns sobre o verdadeiro motivo do adoecimento, mas que a maioria reconhece e seus resultados foram significantes.

A maioria dos profissionais realizam alguma medida de prevenções de adoecimento, contudo foi notório que estes ainda tendem a buscar estratégias de prevenção apenas quando os afastamentos são recorrentes.

Os docentes adoecidos não receberam assistência por parte da Instituição onde trabalhavam ou da unidade que a gerencia. Observamos que os participantes que relataram o desejo desta assistência como forma de valorização profissional não pretendem abandonar a profissão, expondo-se cada vez mais no ambiente de trabalho.

$\mathrm{O}$ afastamento desses profissionais do seu ambiente de trabalho além de elevar os gastos do poder público prejudica o ensino e aprendizagem dos alunos, dada a ausência do professor na sala de aula e substituição por outro profissional. Ressaltamos que o adoecimento representa um risco a saúde desses profissionais.

As dificuldades encontradas foram o quadro de pessoal do departamento de recursos humanos da SME ser limitado dificultando assim a coleta de dados.

Recomenda-se a Secretaria Municipal de Educação a promoção de palestras para os docentes buscando o conhecimento sobre os riscos ocupacionais do seu ambiente de trabalho, visando a adoção de políticas e ações para a redução dos agravos a saúde e prevenção destes, como forma de garantir uma qualidade de vida melhor preservando a saúde e bem estar desses trabalhadores.

\section{REFERÊNCIAS}

1. Amado E. O trabalho dos professores do ensino fundamental: uma abordagem ergonômica. [Dissertação]. Florianópolis: Universidade Federal de Santa Catarina; 2000. $103 \mathrm{f}$. 
2. Assunção AA, Oliveira DA. Intensificação do trabalho e saúde dos professores. Educação \& Sociedade. 2009; 30(107):349-372.

3. Ministério da Saúde (BR). Organização Pan-Americana da Saúde no Brasil. Doenças relacionadas ao trabalho: manual de procedimentos para os serviços de saúde. Brasília: DF; 2001.

4. Mendes R, Dias EC. Da medicina do trabalho à saúde do trabalhador. Rev Saúde Pública.1991; 25(5):341-3491.

5. Associação Brasileira de Saúde Coletiva. Saúde e trabalho: desafio para uma política. Rio de Janeiro: Abrasco; 1991.

6. Alves LA. Uso prolongado da voz em professoras universitárias: uma questão de saúde do trabalhador. [Tese]. Ribeirão Preto: Universidade de São Paulo; 2011. $168 f$.

7. Delcor NS, Araújo TM, Reis EJFB, Porto LA, Carvalho FM, Silva MO et al . Condições de trabalho e saúde dos professores da rede particular de ensino de Vitória da Conquista, Bahia, Brasil. Cad Saúde Pública. 2004; 20(1):187-196.

8. Gressler LA. Introdução à pesquisa: projetos e relatórios. $2^{\circ}$ ed. São Paulo: Loyola; 2004.

9. Ceballos AGC, Carvalho FM, Araújo TM, Reis EJFB. Avaliação perceptivo-auditiva e fatores associados à alteração vocal em professores. Rev bras epidemiol. 2011; 14(2):285-295.

10. Codo W. Educação: carinho e trabalho, Petrópolis: Editora Vozes; 1999.

11. Fontana RT, Pinheiro DA. Condições de saúde auto-referidas de professores de uma universidade regionalCondiciones de auto-reporte de salud de los profesores de una universidad regional. Rev Gaúcha Enferm (Online). 2010; 31(2):270-276.

12. Codo W, Soratto L, Menezes V. Saúde mental e trabalho In: Zanelli JC, BorgesAndrade JE, Bastos AVB. (Org.), Psicologia, organizações e trabalho no Brasil. Porto Alegre: Artmed; 2004.

13. Oliveira JM, Santos PF, Feliciano RG, Assis MM, Cortez EA, Cavalcanti GS. Riscos e doenças ocupacionais do docente universitário de enfermagem: implicações na saúde do trabalhador. J res fundam care (online). 2013; 5(1):3267-3275.

14. Servilha EAM, Arbach MP. Queixas de saúde em professores universitários e sua relação com fatores de risco presentes na organização do trabalho. Distúrb comun. $2011 ; 23(2): 181-191$. 
15. Lima MFEM, Lima-Filho DO. Condições de trabalho e saúde do/a professor/a universitário/a. Ciências e Cognição. 2009; 14(3):62-82.

16. Esteve JM. El mal estar docente. 3. ed. Barcelona: Paidós; 1994.

17. Zacharias J, Mendes AR, Lettnin CC, Dohms KP, Mosquera JJM, Stobäus CD. Saúde e Educação: do mal-estar ao bem-estar docente. Educação Por Escrito. 2011; 2:16-30.

18. Marchesi A. O bem-estar dos professores. Porto Alegre: Artmed; 2008.

19. Guedes AMA, Lima DF, Abreu EF, Sousa GMC. Mal-estar docente: quando a prática compromete a saúde do professor. REVASF. 2013; 2(2):44-54.

20. Fernandes $M H$, Rocha V M, Fagundes AAR. Impacto da sintomatologia osteomuscular na qualidade de vida de professores. Rev bras epidemiol. 2011; 14(2):276-284.

21. Borsoi ICF. Trabalho e produtivismo: saúde e modo de vida de docentes de instituições públicas de Ensino Superior. Cadernos de Psicologia Social do Trabalho. 2012; 15(1):81-100.

22. Chiavegatto CV, Algranti E. Políticas públicas de saúde do trabalhador no Brasil: oportunidades e desafios. Rev. bras. saúde ocup. 2013; 38(127):25-27.

Conflito de interesses: Os autores declaram não haver conflito de interesses.

Como citar este artigo: Silva LA, Fritsch JN, Dalri RCMB, Leite GR, Maia LG, Silveira SE, et al. Riscos ocupacionais e adoecimentos entre professores da rede municipal de ensino. Journal Health NPEPS. 2016; 1(2):178-196. 